\title{
Questions and Countermeasures on Developing General Aviation Industry in China
}

\author{
Yongming Zhu and Yongchao Liu \\ School of Management Engineering, Zheng Zhou University, Henan, China
}

\begin{abstract}
China's general aviation industry has exposed many problems with the low-altitude airspace expanding openness. General aviation is an important part of national economy and defence forces, the development of general aviation has a practical and far-reaching significance. By analysing the China's current general aviation industry, combined with the importance of the development of general aviation, propose some countermeasures and suggestions for the development of China's general aviation industry.
\end{abstract}

\section{Overview on general aviation}

General Aviation refers to the use of civil aircraft to engage in civil aviation activities other than public air transport, including operational flight in industry, agriculture, forestry, fisheries and construction, as well as medical and health, emergency rescue, meteorological detection, Scientific experiments, education and training, cultural and sports aspects of flight activities. General aviation is an important component of modern integrated transportation system, and it is an industry with rich content and active development in civil aviation field. Years ago, due to domestic policy constrains, the development of China's general aviation industry was limited, thus the pace was slow. With the reform and implementation of China's low-altitude airspace management, the obstacles hindering the development of China's general aviation industry are gradually disappearing, and China's general aviation industry also ushered in its golden age of development.

General aviation has a flexible, fast and efficient, environmental adaptability and other characteristics. In the area of emergency relief, general aviation provides humanitarian relief to people facing natural disasters, hunger and war by means of cargo transport and refugee movements. General aviation can provide strong protection for environmental protection and comprehensive management, scientific research and other social public services. It can also provide effective supply in many aviation consumption fields like civil flight, recreation flight, sightseeing flight, aviation education and training [1]. At the same time, with the 2015 low-altitude airspace reform, the private jet market is also about to become the next growth point of promoting domestic demand. All in all, the level of comprehensive development of general aviation, can fully reflect the country's technological level and economic strength. General aviation industry chain as shown in Figure 1.

\section{The Significance of Developing General Aviation}

\subsection{Improve the Traffic Conditions and Promote Opening to the Outside World}

The western region is inland in China, and the terrain hinders the exchange of its property and culture with other regions. The western region covers an area of about 6.86 million square kilometers, accounting for $72 \%$ of the total area. The western region is rich in resources, mineral resources, land, water, and great potential for development, which is the formation of the western characteristics of the economy and an important basis for advantageous industries and favorable conditions.

However, for the development of western resources, relying solely on highways and railways is not enough. The railway network in the western region is thin, the road grade is low, the density is small, the majority of townships in the country that do not have access to roads are concentrated here, and the airport is small, it is inconvenient for large aircraft to take off and land. To carry out the development of the western region and expand the opening-up of the western region, there will certainly be a large flow of personnel and materials. However, the construction of highways and railways takes a long time, and the construction of high-speed railway is very difficult and costly, and it cannot achieve the expected purpose in short time. The flow of goods and personnel will be accelerated because of the development of general aviation in the western region.

\subsection{Promote the logistics industry to upgrade}


Parcel delivery is the most profitable part of the air transport industry. International courier industry in the world is an annual growth rate of $18 \%$. China accounts for a large proportion of the volume of postal services, with an annual turnover of US \$ 2.5 billion and an annual growth rate of $25 \%$, However, due to restrictions on air transport conditions, Speed post business cannot fully reflect the timeliness. In addition, there is a clear market for the development of small, rapid, special transport and postal express services in the region, but it cannot be compared with developed countries due to the influence of mode and price of air transport, but such business is precisely the best opportunity for the general aviation market ${ }^{[3]}$. Air transport is characterized by the one hand, can greatly reduce the goods, parcels from the origin to the destination of the time, bringing business to enhance and higher customer satisfaction; the other hand, in the extensive use of air transport under the premise, land transport will be relatively reduced, to some extent alleviate the large and medium-sized urban transport problems. At the same time, the logistics speed, will in turn promote the development of e-commerce industry, thus changing the entire e-commerce industry and people's lifestyles, greatly enhance people's quality of life.

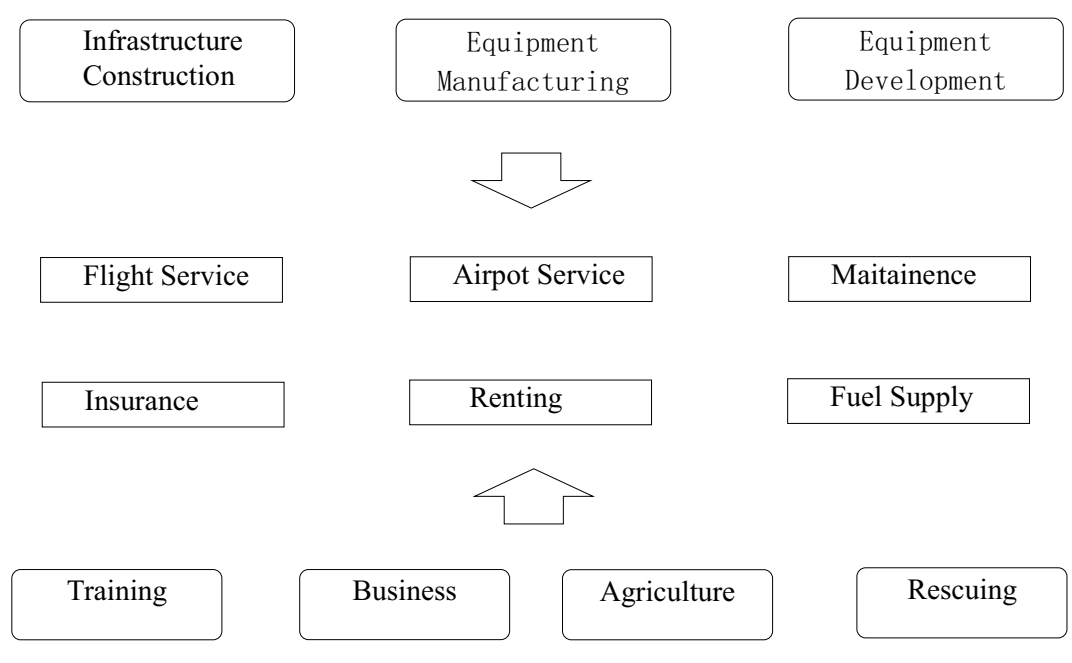

Fig.1. General aviation industry chain

\subsection{Promote the development of aviation rescue enterprises}

In the past, sudden international and social emergencies occurred in China, which were handled by the government to organize temporary institutions. In the case of neither experience nor preparation, rescue effect is seriously affected, in the face of the victims or their families, the international community censure, the government often bear unnecessary pressure. Rescue work in the West has a history of half a century, has been developed to be the 4th largest industry following banking, post and telecommunications, insurance. Adapt to this objective trend, through the international and commercial rescue services to promote the industrialization of China's rescue is an inevitable trend. The birth of the aviation rescue industry has become a requirement of the current situation for the vast territory and less developed traffic in western China.

\subsection{Promote the development of private airc raft market}

China's low-altitude air China's low-altitude airspace reform began in 2015 , the national plan by 10 years will be all the country's airspace is divided into control, surveillance and reporting of three categories of low-altitude airspace for classification management, continue to promote low-altitude airspace reform will further stimulate the private aircraft marketspace reform began in 2015, the national plan by 10 years will be all the country's airspace is divided into control, surveillance and reporting of three categories of low-altitude airspace for classification management, continue to promote low-altitude airspace reform will further stimulate the development of private aircraft market. and the United States more than 0.2 million private aircraft compared to a huge difference. According to market research, the mainland of China has 87.5 million millionaires and 60 million billionaires in the rich, 1/6 of the rich plan to buy a private jet, so projections, China will have 155,800 potential customers. At the same time, because the private airplane market related 
industry chain is relatively long, profit comes from the aircraft pre-purchase, consulting services to pilot training, and follow- up maintenance, operation and fuel consumption.

\section{General Aviation Industry in China}

China's general aviation industry was established in 1952, but the use of relatively was small after the formation, there was a large growth after reforming and opening. According to the CAAC Statistical Yearbook, from 1978 to 2002 , the average annual operating time of general aviation is only about 40,000 flight hours. In 2007, it reached 100,000 flight hours, the highest in history, but mainly in agriculture and forestry operations. From the flight time, flight and flight sorties, the northeastern region of the general aviation industry in the country occupy the largest proportion. Active domestic general aircraft mainly Yun 5 / Yun 5B, transport 11 / transport 12 and other models, belonging to the 70s and

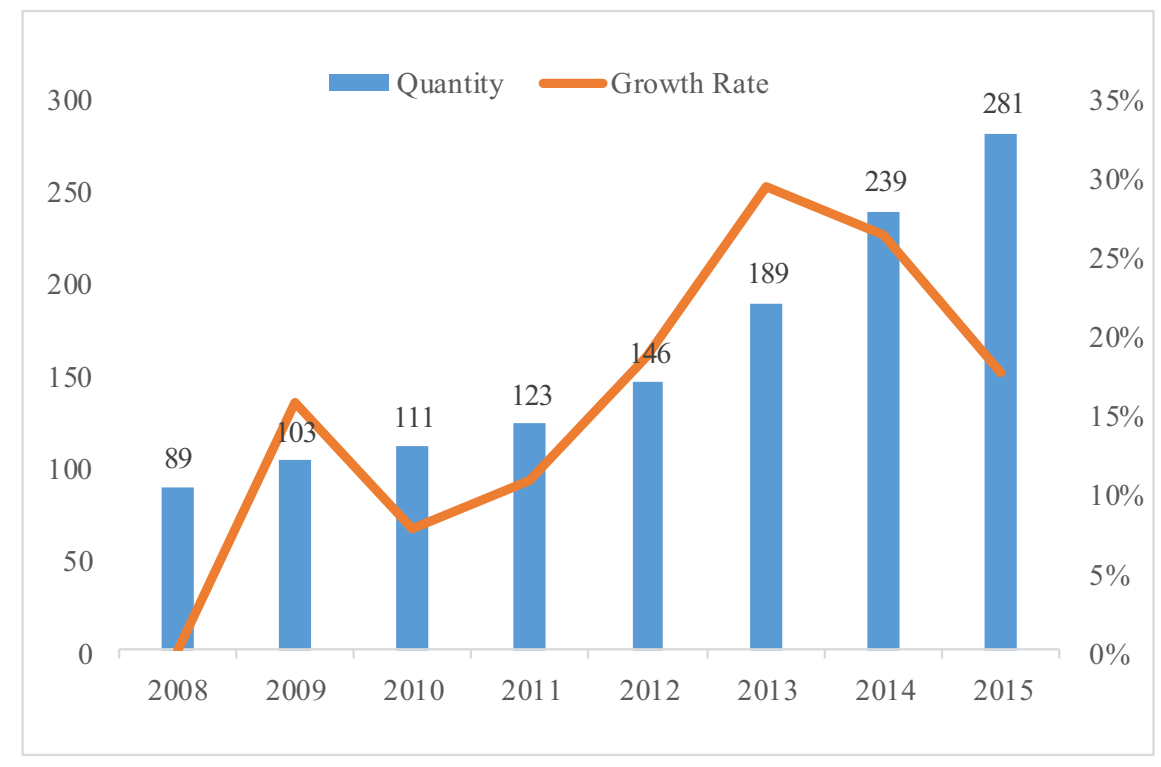

Fig.2. The number of general aviation enterprises in China(2008-2015)

80s products. According to the Civil Aviation Administration of China, "the Civil Aviation Industry Development Statistics Bulletin in 2015" shows that by the end of 2015, access to general aviation business license of 281 general aviation enterprises, among them, there are 72 in North China, 55 in Central South China, 56 in East China, 30 in Northeast China, 37 in Southwest China, 25 in Northwest China, 6 in Xinjiang, General aviation industry to complete the production of 779,300 hours of flight operations, an increase of $15.5 \%$ over the previous year; general aviation enterprises in the total number of airworthiness aircraft registered 1904, of which 508 teaching and training aircraft ${ }^{[2]}$.

From 2016 to 2020, the national low-altitude resources will be fully developed, and gradually formed to supervision, supervision, reporting for the three types of airspace control mode. On this basis, will also build a low-altitude airspace regulatory standard system to achieve service standards and service forms of innovation. Based on the national investment support, to fully mobilize social forces to carry out the construction of aviation service sites, so as to effectively enhance the overall level of general aviation protection, and further improve the flight personnel training system, the establishment of a more standardized industry supervision and evaluation system to enhance general aviation management ability. 2008-2015 The number of general aviation enterprises in China is shown in Figure 2.

\section{The Problems of Developing General Aviation in China}

\subsection{General aviation manufacturing industry development is weak}

With the opening of low-altitude airspace and the increasing market demand, according to the forecast of 2020, China needs 10260 aircraft of various types of peers, including private aircraft, business and trainer demand is growing rapidly, the next 10 years, private and business market demand may reach 100,000. With the strengthening of comprehensive national strength and policy support, China's aviation industry is developing rapidly, but compared with the developed countries, we are still a lot behind, general aircraft and even in its infancy. By the end of 2015, 71.18\% of China's general aviation aircraft was made by foreign manufacturers or joint ventures. At the same time, the development of various models imbalance, rotor aircraft accounted for less than $30 \%$. The high cost of general aviation aircraft and high 
aviation materials tariffs, making the cost of general aviation operations high, seriously limited the development of China's general aviation.

\subsection{Policies and regulations are imperfect}

China's general aviation industry due to the late start, the lack of appropriate laws, regulations and standards system, which to some extent, seriously hampered the development of China's general aviation industry. Such as general aviation airworthiness, airport management regulations are still not perfect. The construction of private airports, private heliports and airports lacks the standards and regulations, and the construction of airports is often costly, which limits the construction of airports. At the same time, airport utilization is not high and airport charges are also raised. Increasing the operating costs of shipping companies. Administrative regulations, industry regulations have not yet formed a standard system, the public airport can arbitrarily refuse to accept general aviation aircraft and arbitrary charges, operation and management has yet to be standardized. General aviation management has no clear attribution. Therefore, the establishment of general aviation in line with China's general aviation requirements of the laws and regulations and standards system has become a top priority.

\subsection{Lack of professional staff}

General aviation industry will become China's new economic growth point but at the same time, also highlights the shortage of professionals in this area the problem. General aviation talent shortage is mainly reflected in two aspects: First, the low quality of personnel. China's general aviation institutions are mostly from veterans, the lack high-quality professionals. Second, a small number of talent. According to the People's Daily reported data, assuming that each aircraft is equipped with two pilots, by 2020 the demand for general aviation pilots will reach 10,000, the pilot gap of 8,000 people. At the same time, China's general aviation industry, recruitment of difficult flight personnel, and ground crew, air control and other personnel scarce, restricted the development of general aviation industry.

\section{Suggestions on Promoting General Aviation Industry Development in China}

\subsection{Improve industrial policies and optimize the macro environment}

In the process of general aviation development, the relevant state departments need to support the industry as soon as possible to develop the industry chain, and develop a new general aviation development in line with the policy. According to the relevant provisions of the international civil aviation, the definition of general aviation, and to determine its legal protection mechanism. The existing laws and regulations to adjust and improve the establishment of ordinary shipping and general aviation in the orderly convergence. The general aviation personnel management, safety management system planning, simplification of management processes, and to develop independent regulations ${ }^{[4]}$.

\subsection{To play the guiding role of the government}

In the future development process, the Government should encourage and support the development of the aviation industry guide, give financial and technical support. Government should allow investors and enterprises to realize that participation in the development and construction of general aviation industry, not only the purchase of aircraft, the aviation-related business, but also can be around the general aviation industry and derived from the business. It can be the construction of airport facilities, which can be the operation and management of aviation operations. It can be engaged in air transportation, photography, sightseeing, emergency rescue, etc., or operate general airport, fixed maintenance base (FBO), land development and so on. At the same time, it may also be considered to participate in the training and assessment of aircraft sales leasing, financing, management and related pilots and management personnel.

In the process of reforming the administrative system, we should strengthen the strength of the government management organization and establish the organization specifications, personnel team and function compilation that are compatible with China's general aviation development.

\subsection{Focus on the relevant personnel training}

General aviation industry chain covering manufacturing, aircraft maintenance and maintenance, flight services and a series of core technologies or expertise required as a support project, which requires practitioners with a high degree of professional knowledge and skills. Due to the lack of core technology and aircraft manufacturing capacity is not high, resulting in a large number of imports to the status quo, the high price of aviation equipment makes the general business and cannot easily purchase aircraft in the general aviation industry, to a certain extent hindered the development of general aviation industry. Therefore, on the one hand, should be policy-oriented, focusing on the aircraft manufacturing industry in personnel training; the other hand, to further improve the flight service post identification mechanism, to 
make up the flight and flight services industry personnel gap, and constantly promote flight skills by specialization to the popularization.

\subsection{Improve the security mechanism}

Coordination of the State Air Traffic Control Committee and other relevant departments to speed up the reform of lowaltitude pilot to improve the airspace use of the environment; in capital, equipment and projects to support the introduction of new technologies to promote the use of ADS-B system to improve command and support capabilities; to encourage social forces development FBO Model; reference to the developed countries' general aviation operations system, improve the general aviation fuel subsidies.

\section{Conclusion and Prospect}

China's general aviation industry started late, slow progress in supporting facilities, imperfect system measures, lack of open air resources, manufacturing capacity and technology is relatively backward, resulting in China's general aviation industry behind the status quo. However, the experience of developed countries tells us the role of general aviation in economic development and social welfare is growing. Constantly improve the system in today, the development of general aviation industry ushered in its golden age.

With the development of society and the progress of science and technology, factors restricting the development of general aviation industry will be gradually eliminated. The general aviation industry plays a vital role in the process of China's opening to the outside world. Under the guidance of the continuous improvement system, it will become another growth point of China's economy. In the near future, we will see a vibrant general aviation industry.

\section{References}

1. Li Chengzhi, Su Daoning. The General Aviation of China: Problems, Reasons and Solutions. Journal of Engineering Studies, 01(2010)

2. Xu Xing. Analysis on Current Dvelopment Situation and Countermeasures of China's General Aviation. Journal of Xi'an Aeronautical University, (06)2014

3. Kang Yong, Zhou Jianmin. Analysis on Development Status, Trend and Countermeasure of General Aviation. Modern Navigation, (05)2012

4. Sun Qinglei. Status Quo and Development Countermeasures of China General Aviation Industry. Shandong Industrial Technology, (17)2015 